\title{
Utilisation of bio-binder made of homogenised peat in crumb rubber-containing composites
}

\author{
Kristine Irtiševa ${ }^{1}$, Vjaceslavs Lapkovskis2 ${ }^{*}$, Viktors Mironovs' ${ }^{2}$, Jurijs Ozolins ${ }^{1}$, Maksim Plohuta ${ }^{1}$, \\ Gaurav Goel ${ }^{3}$, Janis Baronins ${ }^{4}$, and Andrei Shishkin ${ }^{1,4}$
}

1 Rudolfs Cimdins Riga Biomaterials Innovations and Development Centre of RTU, Institute of General Chemical Engineering, Faculty of Materials Science and Applied Chemistry, Riga Technical University, Pulka 3, Riga, LV-1007, Latvia; kristine.irtiseva@rtu.lv (K.I.); jurijs.ozolins@rtu.lv (J.O.); maksims.plohuta@rtu.lv (M.P.); andrejs.siskins@rtu.lv (A.S.)

2 Riga Technical University, Faculty of Mechanical Engineering, Scientific Laboratory of Powder Materials \& Institute of Aeronautics.6B Kipsalas Str., room 110, Riga, LV-1048, Latvia; vjaceslavs.lapkovskis@rtu.lv (V.L.); viktors.mironovs@rtu.lv (V.M.)

3 School of Engineering, London South Bank University, 103 Borough Road, London, SE10AA, UK

4 Maritime Transport department, Latvian Maritime Academy, 12, k-1, Flotes Str., Riga, LV-1016, Latvia (J.B.), (A.S)

* Correspondence: vjaceslavs.lapkovskis@rtu.lv; Tel.: +31 29536301 (V.L.)

\begin{abstract}
The utilisation of the industrial residual products to create new value-added materials and to reduce footprint is a modern challenge of science and industry. Development of the new multifunctional and bio-based composites is an excellent opportunity for complex utilisation of industrial residual products. The study describes the preparation and characterisation of the threephases bio-based composites. The main components are bio-based binder made of peat, devulcanised crumb rubber (DCR) from used tires and part of the fly ash the cenosphere (CS). Threephase composite prepared in the form of a block for investigation of the mechanical properties and density and a form of granules for determination of the water and oil products sorption was investigated. This work investigated the dependence of the properties on the main component DCR and CS fraction. Is found, that maximum compression strength (in block form) observed for composition without CS and DCR addition - 79.3 MPa, the second highest value of compression strength is 11.2 MPa for composition with $27.3 \mathrm{wt} \%$ of CS. For compositions with bio binder content from 17.4 to $55.8 \mathrm{wt} \%$ and with DCR contents in range from 11.0 to $62.0 \mathrm{wt} \%$ compression strength is in range 1.1 to $2.0 \mathrm{MPa}$. Liquid sorption analysis (water and diesel) showed that the maximum saturation of liquids in both cases is set after 35 minutes and ranges from 1.05 to $1.4 \mathrm{~g} \cdot \mathrm{g}^{-1}$ for water and 0.77 to $1.25 \mathrm{~g} \cdot \mathrm{g}^{-1}$ for diesel. It was noted that $90 \%$ of the maximum saturation with diesel fuel comes after 10 minutes and for water after 35 minutes.
\end{abstract}

Keywords: crumb rubber, devulcanised crumb rubber, cenosphere, peat, homogenisation, biocomposite, hybrid material, bio-binder, oil absorption.

\section{Introduction}

Modern world suffering from many challenges such as generated waste increase, by plastic material pollution of nature and at the same time lacking o the new efficient (lightweight, recyclable or decomposable, made of bio-sourced or recycled raw materials) materials. By this research, authors are introducing new biocomposite material made of two recycled materials - a cenosphere and devilcinsed crumb rubber and bio-sourced binder made of natural peat.

Cenosphere (CS) is low-density $\left(0.25-0.55 \mathrm{~g} \cdot \mathrm{cm}^{-3}\right)[1]$, inert, non-toxic, non-flammable powderlike material. With their hollow structure and lightweight properties have emerged as beneficial additives. These materials are derived from coal fly ash which is a significant polluter. Thus, application of cenospheres in composite materials design moves a concept of circular economy 
forward. Cenospheres were chosen for specific properties such as low bulk density, high thermal resistance, good workability, and high strength [1]. Its addition to composite material helps make the material lightweight, improve impact absorption, and acoustic properties[2-5]. Here may also be some adverse effect on physical properties such as reduced compressive strength, increased porosity $[2,6]$. A decision on the trade-off between these different factors such as lightweight, compressive strength, cost-effective etc. is important in developing the material with desired properties.

Every year millions of tires are discarded, across the world, representing a severe threat to the ecology. By the year 2030, there would be up to 5000 million tires to be discarded regularly [7]. Discarded tires often lead to "black pollution" because they are nonbiodegradable and pose a potential threat to the environment [8] because tires have a long life and are nonbiodegradable. The traditional method of waste tires management have been stockpiling or illegally dumping or landfilling, all of which are a short-term solution. A growing amount of scrap tire waste has created a tremendous amount of waste being dumped which is not biodegradable. As Europe is taking the lead in recycling efforts, their use as fuel in the steel industry, cement industry, incineration facilities is being promoted [9]. Alternatively, they are also being used to create running tracks, playgrounds, artificial turfs, railways and in road building [10]. The utilisation of crumb rubber is also gaining traction by incorporating in concrete and rubberised asphalt [11]. This study proposes for the first time use of crumb rubber along with cenosphere, and natural binder peat in developing composite material. These solutions are in line with United Nations sustainable development goals by fostering conversion of waste material into value-added products.

A bio-composite is a category of bio-compatible and environmentally friendly composites that are bio-polymers consisting of natural fibres. Bio-composites are composed of a wide range of organic and inorganic components such as natural and synthetic polymers, polysaccharides, proteins, sugars, ceramics, metal particles and hydrocarbon nanoparticles. Bio-composites come in a variety of forms such as films, membranes, coatings, fibres, and foams. There are several examples of using peat/sapropel binders, such as sapropel concrete, birch wood fiber and sanding dust, hemp shives, for composite materials $[12,13]$. These materials may be in the form of blocks or pellets. The obtained literature studies show the possibilities of using sapropel / peat as a raw material, were in the literature shown the possibilities to use them in the ecological construction were considered, which can be considered as promising materials for building materials and design products $[14,15]$.

An extensive research has been done to improve mechanical properties and functionality of materials, as well as to develop environmentally friendly composite materials [16-18]. The use of biobinders is of significant importance for the development of these bio-composites [19]. Bio-binders, also called bio-polymers, are compounds derived from natural resources and are composed of monomer units that are covalently linked to form larger structures [20,21]. An example of a bio-binder is natural fibres. Natural binders differ in melt flow rate, impact properties, hardness, vapour permeability, coefficient of friction and decomposition. The water absorption of the bio-binder will also varies depending on the chemical composition of the processing conditions of the bio-binder [22]. The production of bio-based polymers using renewable materials has gained significant attention in recent decades in view of achievement the United Nation's Sustainable Development Goals. Latvia and Baltic region are extraordinarily rich with natural peat, one aim of the work is to investigate the possibility of a new application of natural peat - as bio-binder for hybrid composite material.

We are describing for the first-time the utilisation of devulcanised crumb rubber (DCR), homogenised peat (HP) and cenospheres (CS), for composite material development with bio-binder. This research is aimed to answer the question about the main component DCR-HP-CS content in the hybrid effect on composite material properties such as density, mechanical properties, absorption of the water, and oil products. 


\section{Materials and Methods}

\subsection{Raw materials and compositions}

For designing a composite material in two form blocks and granule, a bio-binder made of HP, DCR and CS were used. Three general compositions with CS content 0.0, 5.0 and 10.0 wt $\%$ in a wet mixture were used. For each composition, the amount of DCR 0.0, 5.0, 10.0, 15.0, 20.0, 30.0 wt\% were chosen. Samples designations and composition of the studied materials in block and granules are presented in Table 1 and Table 2. For the specimens, production used wt $\%$ of HP in wet condition (suspension with water content $85 \mathrm{wt} \%$ ), but real DCR, CS and HP after drying also represented in Table 1 and Table 2 for an understanding of the entire composition of studied materials. For a better experience, all studied recopies represented from of ternary composition diagram Table $\mathbf{1 .}$

Table 1 The composition of block and granules in a raw mixture (wet) and after drying, by wt\% (part I).

\begin{tabular}{|l|c|c|c|c|c|c|c|c|c|c|c|c|c|c|}
\hline & \multicolumn{10}{|c|}{ Designation of the composition } \\
\hline & $0-100-0$ & $5-95-0$ & $10-90-0$ & $15-85-0$ & $20-80-0$ & $30-95-0$ & $0-95-5$ & $5-90-5$ & $10-85-5$ & $15-80-5$ & $20-75-5$ & $30-65-5$ \\
\hline \multicolumn{10}{|c|}{ Wet mixture composition [wt\%] } \\
\hline DCR & 0.0 & 5.0 & 10.0 & 15.0 & 20.0 & 30.0 & 0.0 & 5.0 & 10.0 & 15.0 & 20.0 & 30.0 \\
\hline HP & 100 & 95.0 & 90.0 & 85.0 & 80.0 & 70.0 & 95.0 & 90.0 & 85.0 & 80.0 & 75.0 & 65.0 \\
\hline CS & 0.0 & 0.0 & 0.0 & 0.0 & 0.0 & 0.0 & 5.0 & 5.0 & 5.0 & 5.0 & 5.0 & 5.0 \\
\hline & & & 0 & Dried composite material formulation [wt\%] & & \\
\hline DCR & 0.0 & 27.3 & 44.2 & 55.8 & 64.1 & 75.4 & 0.0 & 22.1 & 37.2 & 48.1 & 56.3 & 68.0 \\
\hline HP & 100 & 72.7 & 55.8 & 44.2 & 35.9 & 24.6 & 72.7 & 55.8 & 44.2 & 35.9 & 29.6 & 20.6 \\
\hline CS & 0.0 & 0.0 & 0.0 & 0.0 & 0.0 & 0.0 & 27.3 & 22.1 & 18.6 & 16.0 & 14.1 & 11.3 \\
\hline
\end{tabular}

Table 2 The composition of block and granules in a raw mixture (wet) and after drying, by wt\% (part II)

\begin{tabular}{|l|c|c|c|c|c|c|}
\hline & \multicolumn{7}{|c|}{ Designation of the composition } \\
\hline & $0-90-10$ & $5-85-10$ & $10-80-10$ & $15-75-5$ & $20-70-10$ & $30-60-10$ \\
\hline \multicolumn{7}{|c|}{ Wet mixture composition [wt\%]* } \\
\hline DCR & 0.0 & 5.0 & 10.0 & 15.0 & 20.0 & 30.0 \\
\hline HP & 90.0 & 85.0 & 80.0 & 75.0 & 70.0 & 60.0 \\
\hline CS & 10.0 & 10.0 & 10.0 & 10.0 & 10.0 & 10.0 \\
\hline & \multicolumn{7}{|c|}{ Dried composite material formulation [wt\%] } \\
\hline DCR & 0.0 & 18.6 & 32.1 & 42.3 & 50.3 & 62.0 \\
\hline HP & 55.8 & 44.2 & 35.9 & 29.6 & 24.6 & 17.4 \\
\hline CS & 44.2 & 37.2 & 32.1 & 28.2 & 25.1 & 20.7 \\
\hline
\end{tabular}




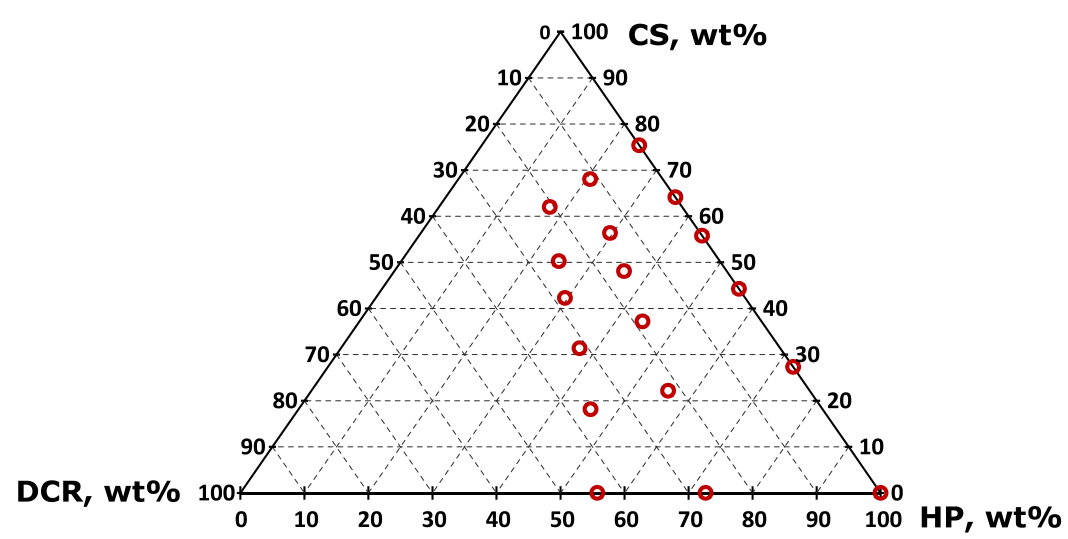

Figure 1. Ternary diagram of the dried composed material composition, by $w \mathrm{t} \%$.

To be used as a bio-based binder, natural peat (deposition Keizerpurvs, Cesis, Latvia) was preliminary processed hydrocavitation process. The raw peat (humidity 65-70\%) was mixed with water and processed in high-speed multi-disc mixer-disperser (HSMD) with cavitation effect for obtaining the homogeneous water-peat slurry with dry matter contents $15 \pm 1 \mathrm{wt} \%$. Raw peat agglomerates (a) before and treated peat particles (extracted from the suspension) after treatment by HSMD are shown in Figure 2.
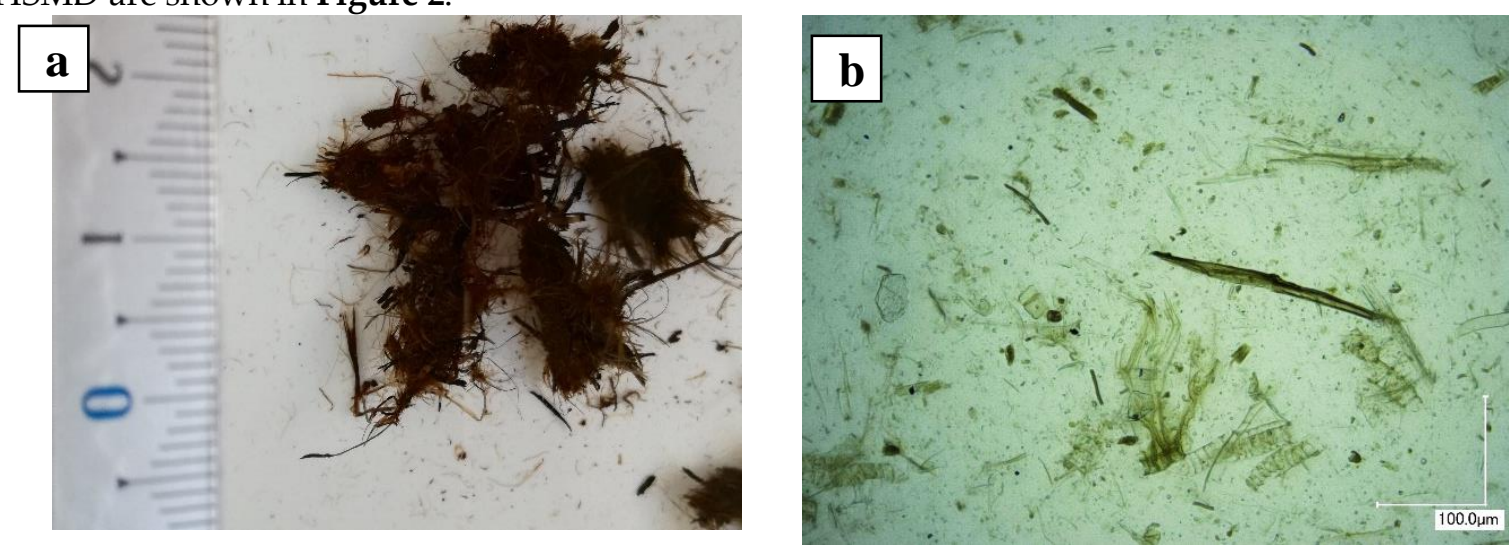

Figure 2. Peat agglomerates (a) before and peat particles (b) after treatment by HSMD.

The rotation speed of HSMD used in experiments was 8500-9000 $\mathrm{min}^{-1}$, and linear velocity of the working teeth was from 70 to $80 \mathrm{~m} \cdot \mathrm{sec}^{-1}$. Therefore, the cavitation conditions required for slurry homogenisation were ensured. The technological scheme and HSMD common view is given in Figure 3. The treatment time by HSMD was $5 \mathrm{~min}$, and $45 \mathrm{~kg}$ of the total amount of HP to ensure homogenous sludge-like HP. 

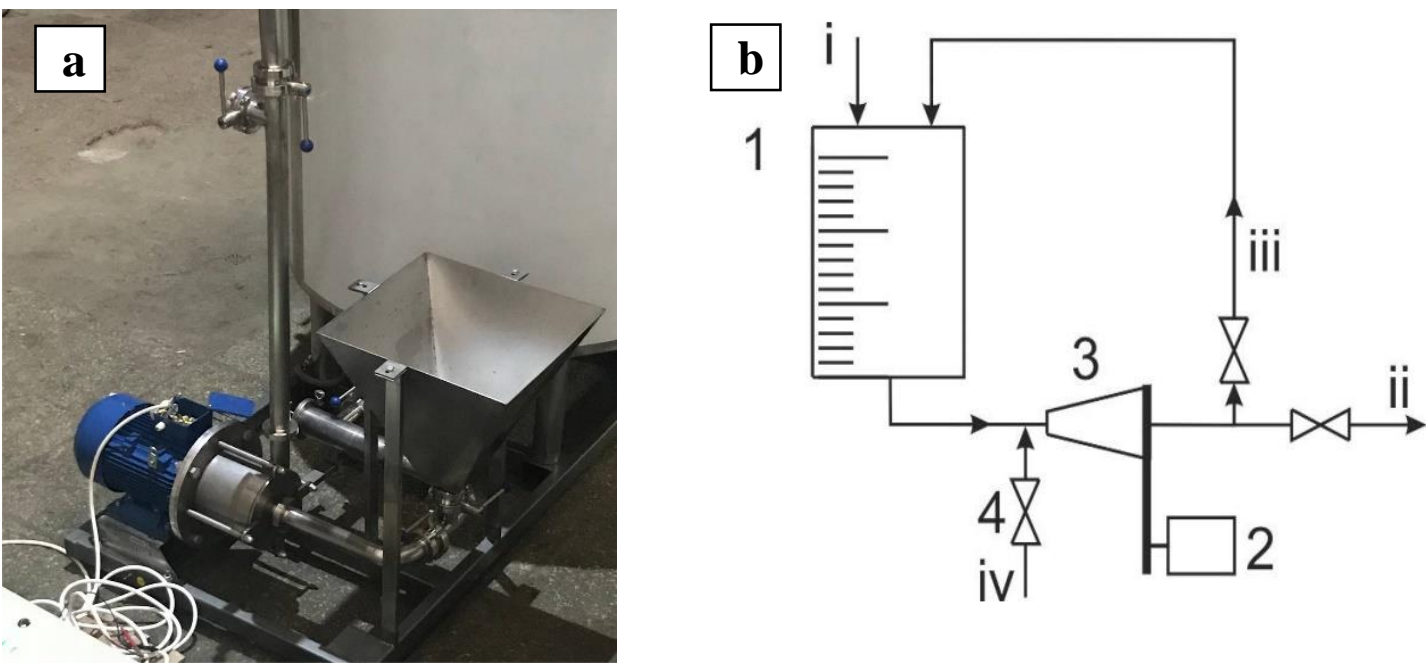

Figure 3. HSMD common view (a), homogenizer principial scheme (b), where: 1 - peat slurry tank; 2 - electric motor; 3 - HSMD; 4 - valve for extra component supply funnel (iv); i - water supply; ii - slurry output; iii - recirculation flow.

The CS used in the experiments were supplied by Biothecha Ltd. (Riga, Latvia). Chemical composition is: $\mathrm{SiO}_{2}-53.8 \pm 0.5 \% ; \mathrm{Al}_{2} \mathrm{O}_{3}-40.7 \pm 0.7 \% ; \mathrm{Fe}_{2} \mathrm{O}_{3}-1.0 \pm 0.2 \% ; \mathrm{CaO}-1.4 \pm 0.2 \% ; \mathrm{MgO}-0.6 \pm 0.2$ $\% ; \mathrm{Na}_{2} \mathrm{O}-0.5 \pm 0.1 \% ; \mathrm{K}_{2} \mathrm{O} 0.4 \pm 0.1 \%$. Loss of ignition is $1.1 \pm 0.1 \%$. The grading composition is $<63 \mu \mathrm{m}$ $-1.70 \mathrm{wt} \%, 63-75 \mu \mathrm{m}-3.86 \mathrm{wt} \%, 75-150-94.30 \mathrm{wt} \%$. CS average wall thickness is from 7 to $15 \mu \mathrm{m}$. A detailed characterisation, including chemical analysis, particle size and morphology, has been published in $[2,3,23]$. The common appearance of the CS is represented in Figure 4.
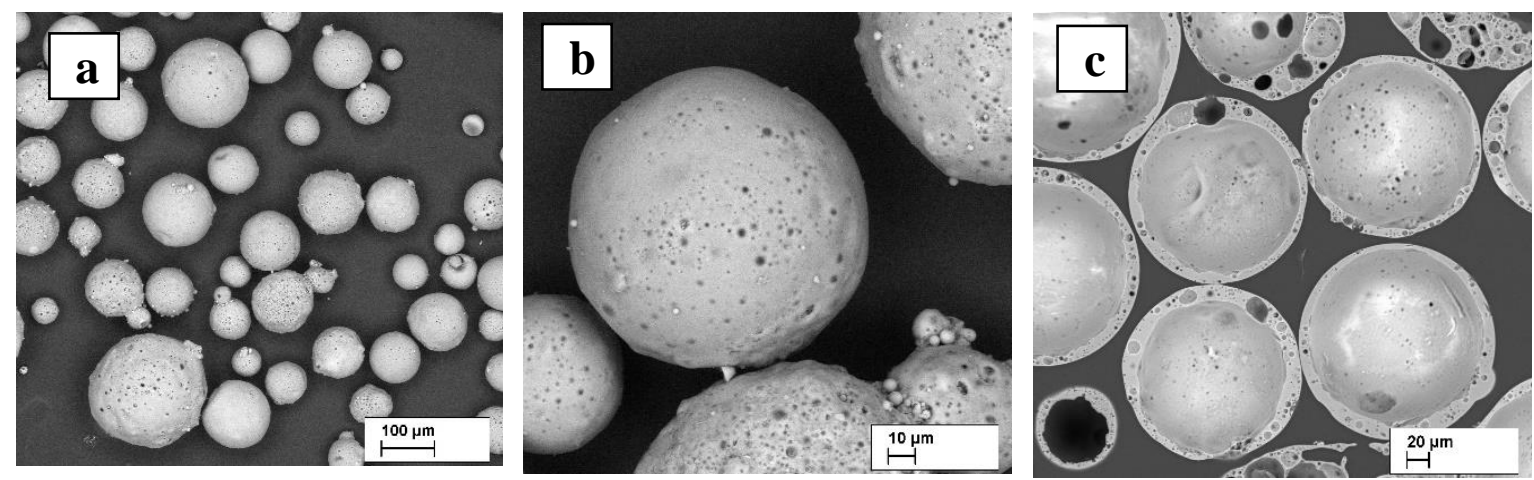

Figure 4. Scanning electron microscopy images of CS typical appearance at x100 times magnification (a), at x500 (b) and cross-section X200 times magnification.

DCR used for current research is produced using patented [24] mechano-chemical treatment technology at a semi-industrial pilot plant located in Riga (Latvia). A method comprises the processing of crumb rubber by grinding rolls at temperature $60-70{ }^{\circ} \mathrm{C}$ with the addition of devulcanisation chemicals. End-products represent a sponge-like aggregate of devulcanised crumb rubber. For the DCR milling-deagglomeration impact-type disintegrator DESI-15 (Desintegraator Tootmise OÜ, Estonia) at a rotation speed, $3000 \mathrm{~min}^{-1}$ was used. The DCR was milled in direct mode five times (passes). For the present study, 0,25-2,0 mm fraction was used (Figure 5.) More details about CDR milling, particle size distribution and morphology is described by V. Lapkovskis et all. [25]. 

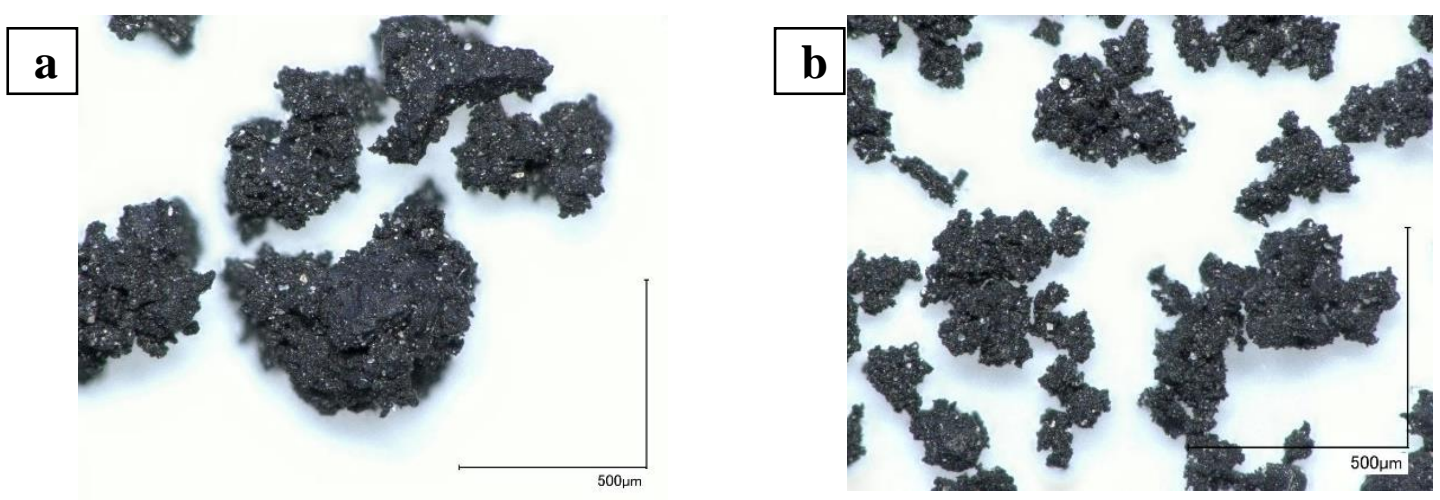

Figure 5. Digital optical micrographs of DCR 0.25-0.5 mm (a) and $<0.25 \mathrm{~mm}$ (b) size.

For the production of the block, the components were manually mixed until the homogeneous mix, then placed into plastic moulds 140x180x20 mm. Samples were dried at room temperature for 20 days. After drying all specimens have been demoulded and left for ambient drying for ten days. To remove residual humidity, samples were dried at $105^{\circ} \mathrm{C}$ for $48 \mathrm{~h}$.

For the blocks granules, the components were manually mixed until the homogeneous mix, then placed rotary drum granulator with drum diameter $950 \mathrm{~mm}$ and rotation speed $80 \mathrm{~s}^{-1}$. Samples were dried at room temperature for 2 days. In order to remove residual humidity, specimens were dried at $105{ }^{\circ} \mathrm{C}$ for $48 \mathrm{~h}$. Standard production scheme of composite blocks and granules is demonstrated in Figure 6 .

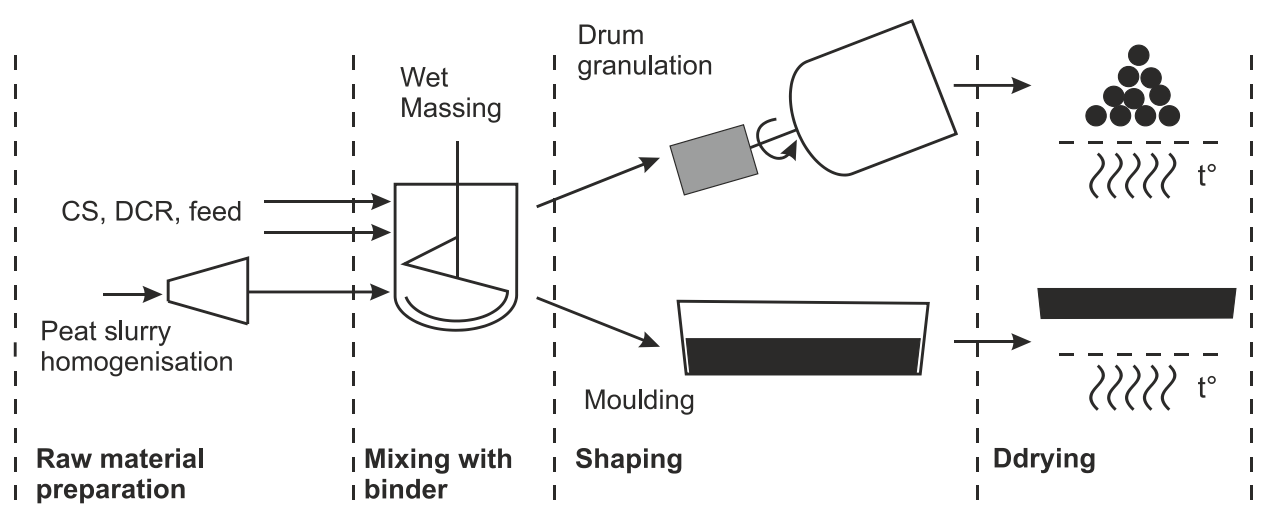

Figure 6. On the bio-based binder composite material in the shape of granules and block principal scheme.

\subsection{Characterisation methods}

\subsubsection{Liquid adsorption}

Determination of liquid (water and oil products) absorption was performed by immersing specimens in the liquid and checking the weight in a specific interval. The experiments were repeated five times for each composition/liquid, with a margin of error relative to the mean for each experiment. The liquid absorption $(\mathrm{W})$ is calculated according to formula (1).

$$
W=\frac{m_{1}-m_{0}}{m_{0}}
$$

Where is:

$\mathrm{m}_{1}$ - a mass of the sample saturated with liquid, g; mo - dry mass (before immersion) of the sample, g; $\mathrm{W}$ - liquid absorption $\mathrm{g} / \mathrm{g}$. 


\subsection{Used equipment and measurements devices}

High-speed multi-disc mixer-disperser with cavitation effect (HSMD)[26-28] for obtaining homogeneous water peat slurry with dry matter content $15 \pm 1$ wt $\%$. For the moisture content is determined using moisture analyser Kern MRS 120-3. Measurements are repeated 7 times using the standard deviation is determined standard error from the arithmetic mean. The Clatronic Multi Food Processor KM3350 (Clatronic GmbH, Kempen, Germany) with stainless steel container with a rubbercoated anchor-type mixer was used for wet mixture preparation at a rotation speed of $60 \mathrm{~min}-1$

For specimens micro-optical inspection digital light microscope Keyence VHX-1000 (Keyence Corp. Osaka, Japan) equipped with digital camera 54MPx and VH-112 Z20R/Z20W lens and scanning electron microscopy (SEM) - field emission SEM Tescan Mira/LMU and optical microscopy were used.

\section{Results}

\subsection{Morphology of the obtained biocomposite block and granules}

The most characteristic difference of obtained bio-composites morphology in the form of block and granules is represented on Figure 7. The biggest difference in the appearance of the obtained composites is noted for block-shaped material with 0,5 and $10 \mathrm{wt} \%$ of CS. The specimens containing $100 \mathrm{wt} \%$ of HP (composition 0-100-0) was strongly cracked after drying (Figure 7a), what is demonstrate high shrinkage, what is obviously, due to used HP without any additive contain $85 \mathrm{wt} \%$ of water. Detailed visual inspection of the parts of the cracked specimen, using magnification X50 times (Figure 7d) demonstrates a dense non-porous structure with white, crystal-like inclusions sand particles. Analyzing them by applying of polarized light is concluded that this is mainly quartz particles and admixture of the limestone, which is a natural component of Baltic region peat. Addition of the $5 \mathrm{wt} \%$ of CS and/or $5 \mathrm{wt} \%$ of DCR strongly minimise shrinkage and cracking, the typical appearance of the $0-95-5,5-95-0$ or 5-95-5 specimens is demonstrated by (Figure 7b). But in comparison with highly-loaded composition 20-70-10, its geometry still differ from mould shape (Figure 7b, 7c). But is necessary to consider that real content of fillers - CS and DCR is much higher (Table 1, Table 2), because of water loss from HP is increased CS and CDR content in the composite. Specimens 0-95-5, 5-95-0 or 5-95-5 after drying has 0-72.7-27.3, 27.3-72.7-0 and 22.1-55.8-22.1 CDR$\mathrm{HP}-\mathrm{CR}$ mass ratio (or weight \%) respectively. Effect of the shrinkage ratio decrease was noted by several works $[2,29,30]$ mainly with a ceramic matrix material, where it is traditionally observed high shrinkage during the drying and firing [2,31].

In contrasts with block material, 0-100-0 granules have no significant morphological differences with other composition specimens - (Figure 7g-7j). In common, all made granules characterised by near-spherical shape and particle size distribution for all composition was: 1-2 mm - 7-15\%, 2-6 mm - 10-20 and 6-10 mm - 60-70 wt\%. 

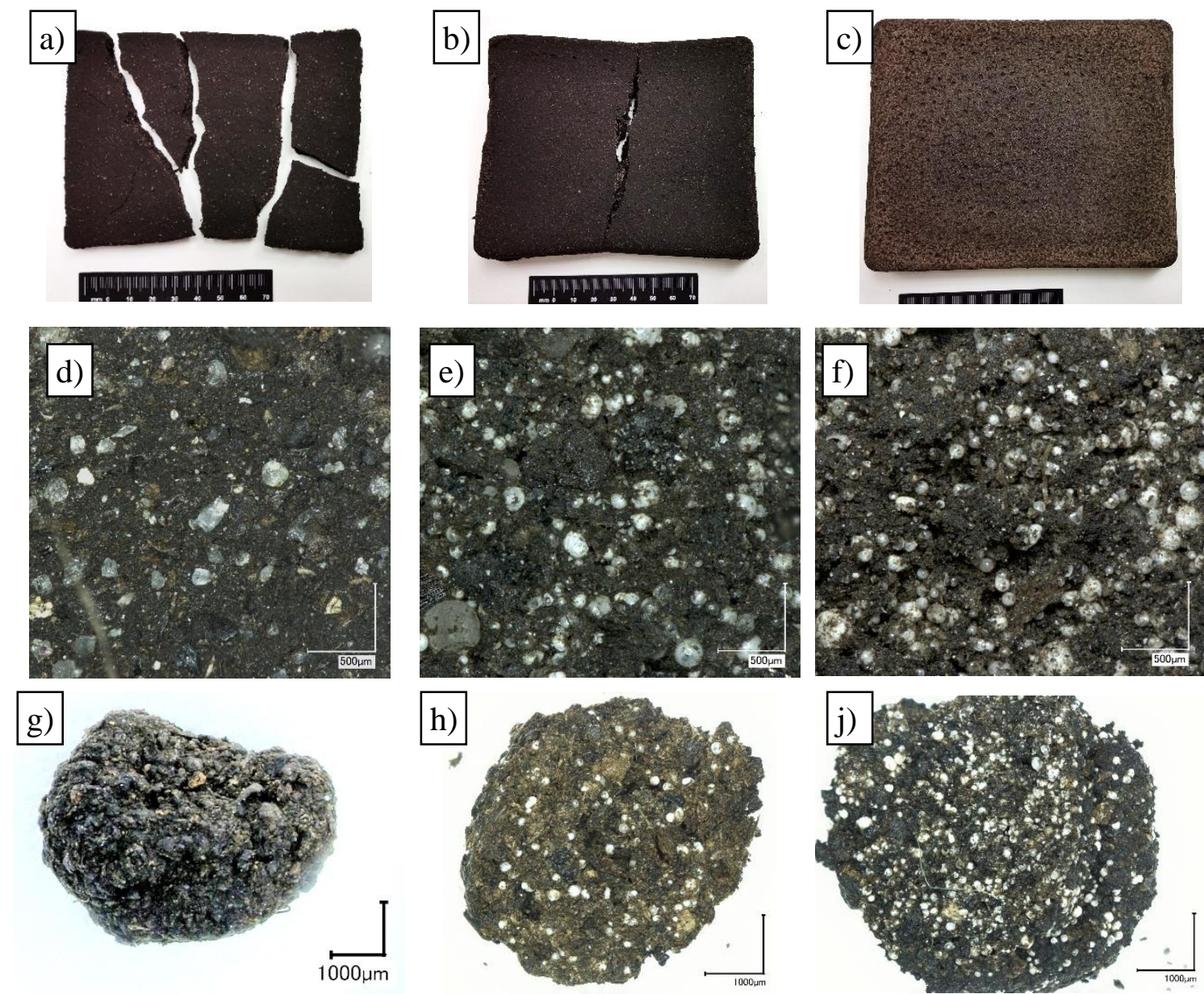

Figure 7. Images of CS-DCR-HP composite material: common appearance of dried block 0-100-0 (a), 5-90-5 (b) and 20-100-10 (c); micro images of blocks 0-100-0 (d), 5-90-5 (e), 20-70-10 (f) fractures: and granules: 0-100-0 (g), 5-90-5 (h), 20-70-10 (j) common appearance.

\subsection{Mechanical properties and density of the obtained bio-composite block and granules}

Obtained composites in from of blocks were tested for the compression strength and apparent density. The results are represented in a combined diagram in Figure 8. Is seen, that exclusively high compression strength $-79 \mathrm{MPa}$ corresponds to the pure peat-based bio-binder (0-100-0). Second highest compression strength - 11 MPa corresponds to the 0-100-5 composition with $5 \mathrm{wt} \%$ of CS in a raw wet mixture or $27.3 \mathrm{wt} \%$ in the composite material after drying (Table 1). Observation the parts of the cracked specimens 0-100-5 (with $27.3 \mathrm{wt} \%$ of CS) it has dense structure without cracks or voids the same as $0-100-0(100 \mathrm{wt} \%$ of $\mathrm{HP}$, Figure $7 \mathrm{~d})$ specimens. A significant difference in mechanical properties (79.3 and $11.1 \mathrm{MPa}$ ) could be explained by the presence of the filler with lower mechanical properties than quartz and limestone particles - CS. Introduction of the $27.3 \mathrm{wt} \%$ of the DCR leads to decreasing of compression strength to $7.6 \mathrm{MPa}$.

Increase of the CDR in composite in all of the studied cases lead to a significant decrease of compression strength, up to $1.5 \pm 0.4 \mathrm{MPa}$, but not less than $1.1 \mathrm{MPa}$ (10-80-10 and 20-70-10). 


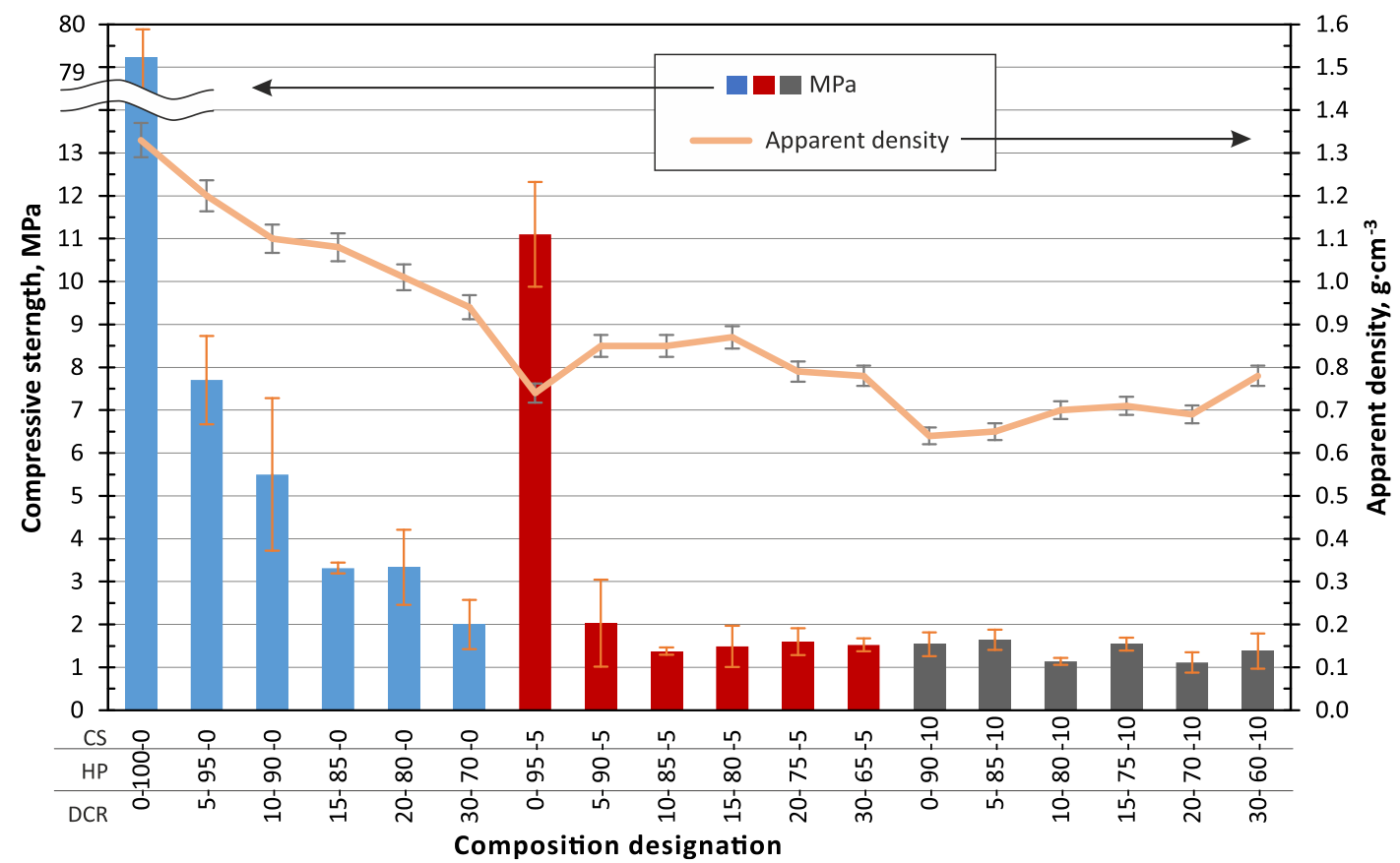

Figure 8. Dependence of the apparent density and compressive strength of bio-composite I shape of a block on the DCR and CS fraction. The composition of DCR HP and CS fraction by indicated weight $\%$ in the wet mixture.

By applying the determined physical-mechanical properties data of the obtained samples to M. F. Ashby's [32] compression strength and density summary diagram (Figure 9), it can be concluded that the obtained material is characterised by relatively low density and relatively high strength characteristic of bio-composites, which is one of the aims of this work. Pure bio-binder (0-100-0) composite material in coordinates $\mathrm{MPa}-\mathrm{kg} \cdot \mathrm{m}^{-3}$ located in the upper zone of the polymer and elastomers area. Compositions $5-\mathrm{XX}-\mathrm{X}$ and $10-\mathrm{XX}-\mathrm{X}-$ with 5 and $10 \mathrm{wt} \%$ of DCR content in wet mixture coordinates $\mathrm{MPa}-\mathrm{kg} \cdot \mathrm{m}^{-3}$ belongs to the lower zone of the natural material area.

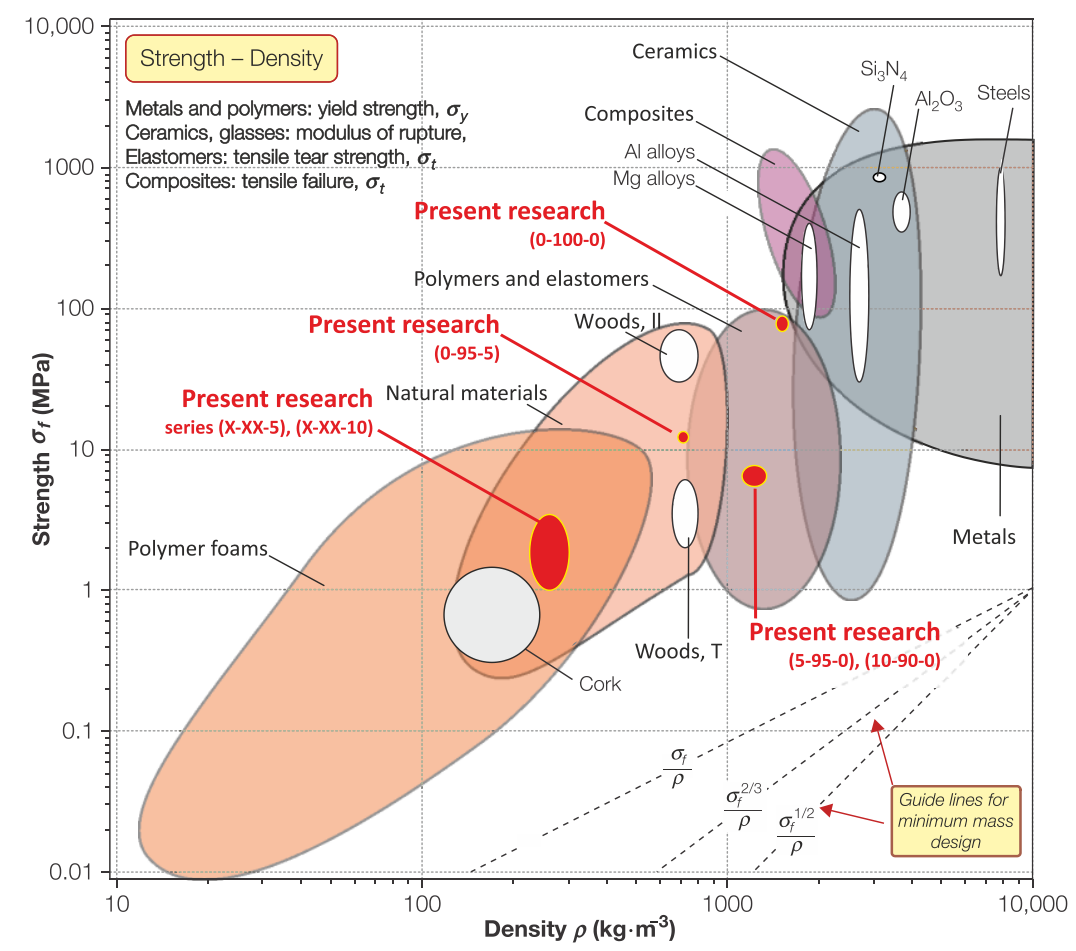


Figure 9. Influence on the compliance of studied bio-composite (in form-factor of a block) with typical materials demonstrated in Ashby classification diagram (adapted from [32]).

\subsection{Sorption of liquids in the structure of the granulated bio-composites}

Obtained biocomposite granules were applied for sorption of water and oil products (diesel). Sorption kinetics were estimated for biocomposite by using diesel fuel as model-compound, as demonstrated in Figure 10 and Figure 11. All samples reach 90\% sorbent water uptake capacity in 25-30 minutes but maximal saturation up to 35-45 min Figure 10. All series of the samples demonstrated near 1.0 $\mathrm{g} \cdot \mathrm{g}^{-1}$ water sorption capacity saturation conditions. For the diesel $90 \%$ sorbent uptake capacity was noted in shorter time - in 5-10 minutes, but maximal saturation up to 35-45 min Figure 11. All series of the samples demonstrated from 1.0 to $1.5 \mathrm{~g} \cdot \mathrm{g}^{-1}$ diesel sorption capacity at equilibrium conditions. Highest adsorption capacity is to $1.5 \mathrm{~g} \cdot \mathrm{g}^{-1}$ for specimen $30-65-5$, which corresponds to $68.0-20.6-$ 11.3 ratio of components in a dry composite. It is necessary to admit that maximal saturation by liquids is for diesel, by except 30-70-0 maximal saturation was reached after 3-5 minute.

On the Figure 12 is demonstrated water and diesel uptake capacity, in $\mathrm{g} / \mathrm{g}$ for granules is clearly seen that for most cases (by except $30-70-0,5-90-5,15-80-5$ and $20-75-5$ ) is greater sorption for water. For the composition series $\mathrm{XX}-\mathrm{XX}-0$ and $\mathrm{XX}-\mathrm{XX}-10$ water uptake significantly higher from 10 to $50 \%$, but for $\mathrm{XX}-\mathrm{XX}-5$ series are nod showing big differences. However re-calculating sorption capacity from, mass ratio $\left[\mathrm{g} \cdot \mathrm{g}^{-1}\right]$ to sorbent mass to absorbed liquid volume $\left[\mathrm{cm}^{3} \cdot \mathrm{g}\right]$, taking in to account diesel density $0.85 \mathrm{~g} \cdot \mathrm{cm}^{-3}$, sorbent capacity for diesel will be higher for $15 \%$.

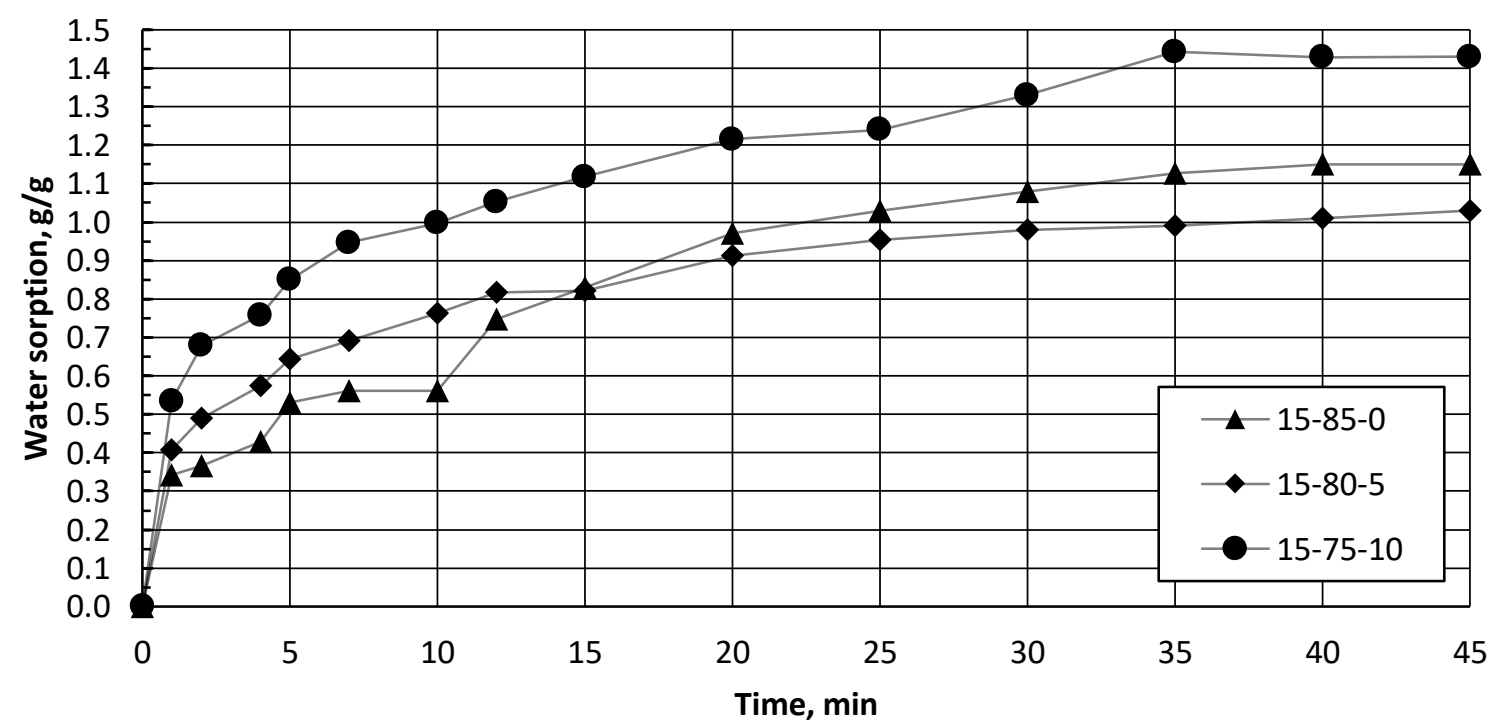

Figure 10. Water adsorption, in $\mathrm{g} / \mathrm{g}$ for granules compositions series with $0 \mathrm{wt} \%$ (a), $5 \mathrm{wt} \%$ (b) and $10 \mathrm{wt} \%$ (c) of CS. 


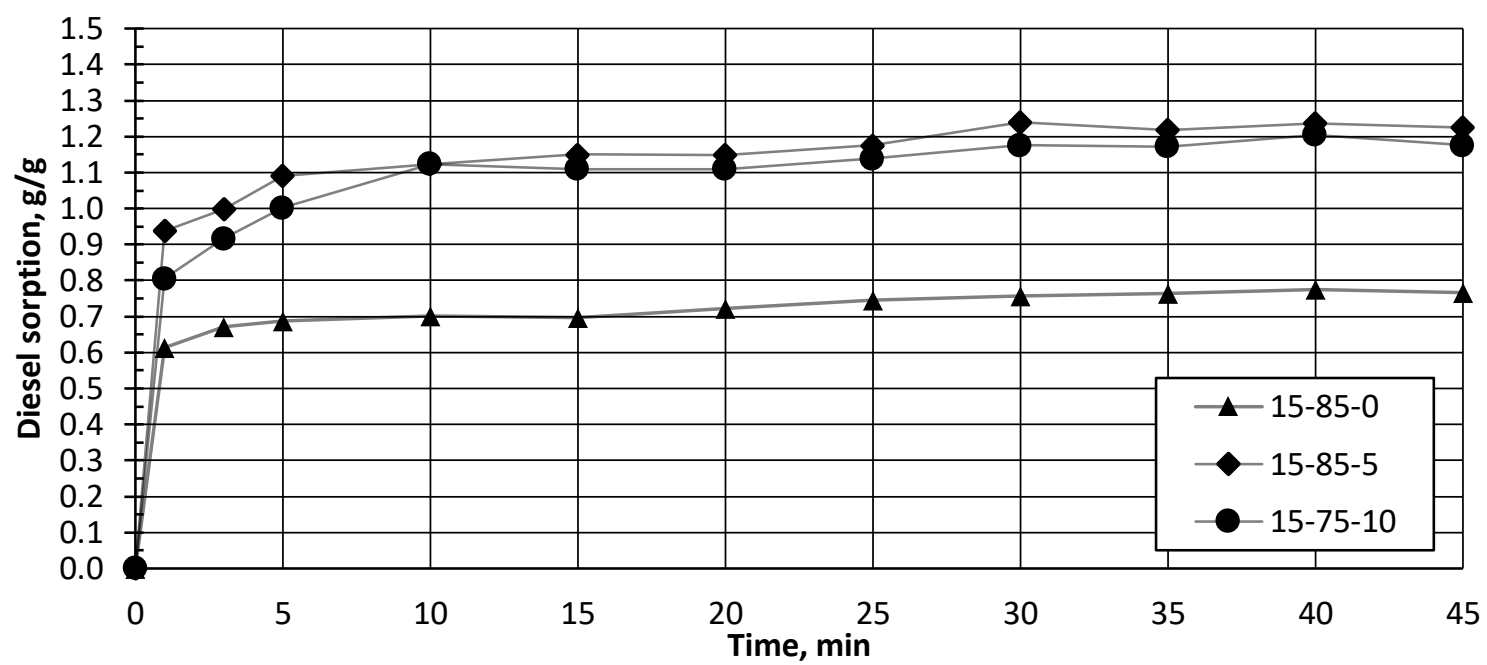

Figure 11. Diesel adsorption, in $\mathrm{g} / \mathrm{g}$ for granules compositions series with $0 \mathrm{wt} \%$ (a), $5 \mathrm{wt} \%$ (b) and $10 \mathrm{wt} \%$ (c) of CS.

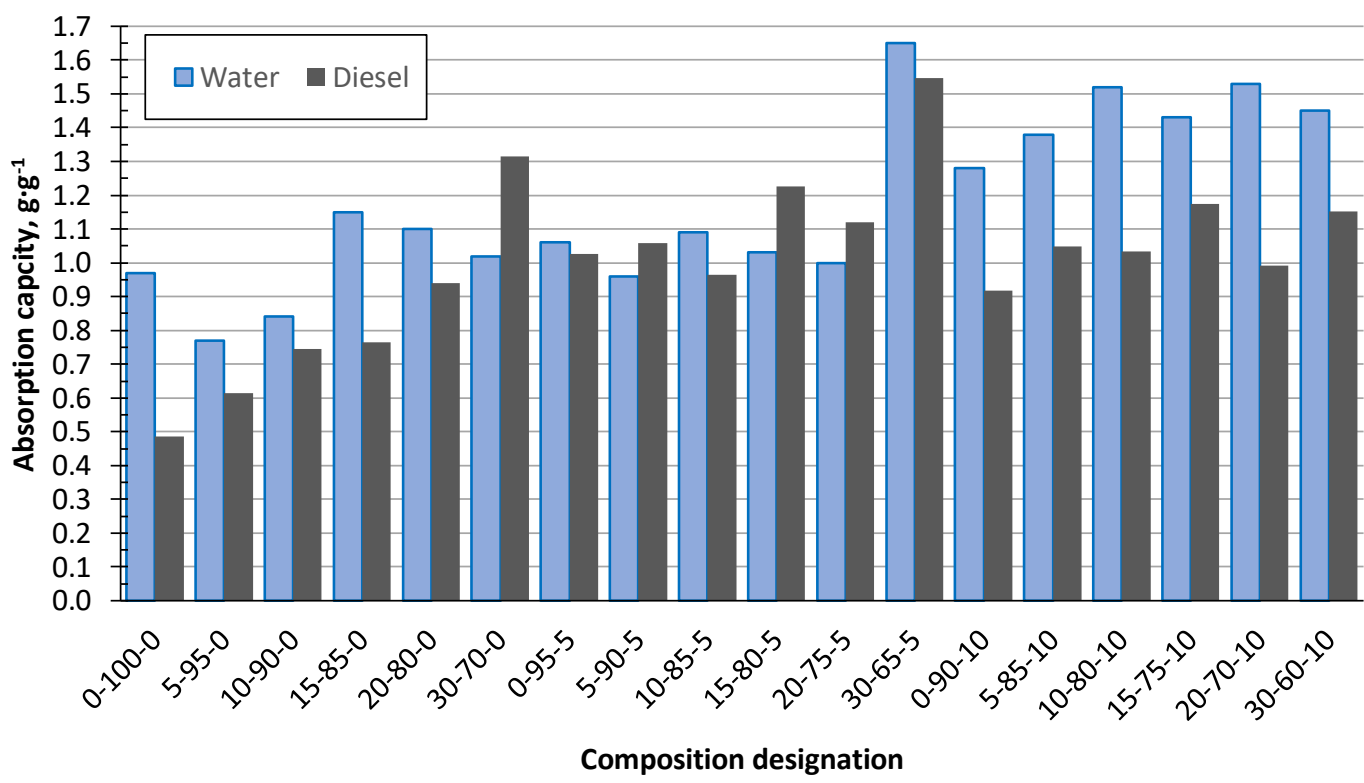

Figure 12. Sorbent water and diesel uptake capacity, in $\mathrm{g} / \mathrm{g}$ for granules compositions

\section{Conclusions}

In current research three-phase composite material containing homogenised peat as bio-binder for water and oil products were produced in form of block and granules was produced for the first time. Obtained material in form of block cancerised by good combination of compression strength and density.

Obtained granulated sorbent containing 68.0-20.6-11.3 of CDR HP and CS has demonstrated up to $1.5 \mathrm{~g} \cdot \mathrm{g}^{-1}$ maximal sorption capacity for diesel.

Composite material with CS content $27.3 \mathrm{wt} \%$ is characterised by highest value (by except the pure bio-binder) compression strength $11.2 \mathrm{MPa}$ and at the same time apparent density $0.75 \mathrm{~g} \cdot \mathrm{cm}^{-3}$. $\mathrm{HP}$ as bio-binder and CS as lightweight filler could become a perspective material for lightweight bio-based structures design. Further investigations of the influence of CS content on the CS-HP biocomposite is foreseen.

Author Contributions: Conceptualisation, A.S. and V.L.; methodology, A.S., K.I. and V.L.; validation, A.S., K.I., J.O., J.B. and V.L.; investigation, V.L., A.S., K.I., J.B, G.G and M.P.; data curation, A.S., M.P. and K.I.; writingoriginal draft preparation, A.S., K.I. and V.L.; writing - review and editing, A.S., V.L., J.B. and G.G.; visualisation, 
A.S. and K.I.; supervision, V.M. and J.O.; project administration, V.L. and V.M.; funding acquisition, V.L. and V.M. All authors have read and agreed to the published version of the manuscript.

Funding: This research was equally funded by two grants: 1) by Riga Technical University's Doctoral Grant programme; 2) the European Regional Development Fund within the Activity 1.1.1.2 "Post-doctoral Research Aid" of the Specific Aid Objective 1.1.1 "To increase the research and innovative capacity of scientific institutions of Latvia and the ability to attract external financing, investing in human resources and infrastructure" of the Operational Programme "Growth and Employment" (No. 1.1.1.2/VIAA/1/16/175).

Conflicts of Interest: The authors declare no conflict of interest.

\section{References}

1. Ranjbar, N.; Kuenzel, C. Cenospheres: A review. Fuel 2017, 207, 1-12.

2. Rugele, K.; Lehmhus, D.; Hussainova, I.; Peculevica, J.; Lisnanskis, M.; Shishkin, A. Effect of Fly-Ash Cenospheres on Properties of Clay-Ceramic Syntactic Foams. Materials (Basel). 2017, 10, 828.

3. Shishkin, A.; Mironov, V.; Zemchenkov, V.; Antonov, M.; Hussainova, I. Hybrid Syntactic Foams of Metal - Fly Ash Cenosphere - Clay. Key Eng. Mater. 2016, 674, 35-40.

4. Santa Maria, J.A.; Schultz, B.F.; Ferguson, J.B.; Gupta, N.; Rohatgi, P.K. Effect of hollow sphere size and size distribution on the quasi-static and high strain rate compressive properties of $\mathrm{Al}-\mathrm{A} 380-\mathrm{Al} 2 \mathrm{O} 3$ syntactic foams. J. Mater. Sci. 2014, 49, 1267-1278.

5. Tatarinov, A.; Shishkin, A.; Mironovs, V. Correlation between ultrasound velocity, density and strength in metal-ceramic composites with added hollow spheres. IOP Conf. Ser. Mater. Sci. Eng. 2019, 660, 012040.

6. Jiang, F.; Zhang, L.; Mukiza, E.; Qi, Z.; Cang, D. Formation mechanism of high apparent porosity ceramics prepared from fly ash cenosphere. J. Alloys Compd. 2018, 749, 750-757.

7. Thomas, B.S.; Gupta, R.C.; Panicker, V.J. Recycling of waste tire rubber as aggregate in concrete: durability-related performance. J. Clean. Prod. 2016, 112, 504-513.

8. Nehdi, M.; Khan, A. Cementitious Composites Containing Recycled Tire Rubber: An Overview of Engineering Properties and Potential Applications. Cem. Concr. Aggregates 2001, 1, 3-10.

9. Ferronato, N.; Torretta, V. Waste Mismanagement in Developing Countries: A Review of Global Issues. Int. J. Environ. Res. Public Health 2019, 16, 1060.

10. Llompart, M.; Sanchez-Prado, L.; Pablo Lamas, J.; Garcia-Jares, C.; Roca, E.; Dagnac, T. Hazardous organic chemicals in rubber recycled tire playgrounds and pavers. Chemosphere 2013, 90, 423-431.

11. Mashaan, N.S.; Ali, A.H.; Karim, M.R.; Abdelaziz, M. A Review on Using Crumb Rubber in Reinforcement of Asphalt Pavement. Sci. World J. 2014, 2014, 1-21.

12. Vincevica-Gaile, Z.; Stankevica, K.; Irtiseva, K.; Shishkin, A.; Obuka, V.; Celma, S.; Ozolins, J.; Klavins, M. Granulation of fly ash and biochar with organic lake sediments - A way to sustainable utilization of waste from bioenergy production. Biomass and Bioenergy 2019, 23-33.

13. Obuka, V.; Šinka, M.; Kḷaviņš, M.; Stankeviča, K.; Korjakins, A. Sapropel as a binder: Properties and 
application possibilities for composite materials. In Proceedings of the IOP Conference Series: Materials Science and Engineering; 2015; Sēj. 96.

14. Obuka, V.; Sinka, M.; Nikolajeva, V.; Kostjukova, S.; Lazdina, L.; Klavins, M. Sapropel and lime as binders for development of composite materials. In Proceedings of the European Biomass Conference and Exhibition Proceedings; 2017.

15. Kḷaviņš, M. Kūdra un sapropelis - ražošanas, zinātnes un vides sinerğija resursu efektīvas izmantošanas kontekstā; Kḷaviņš, M., Red.; Ozola, Rūt.; ResProd: Riga, 2017; ISBN ISBN 978-9934-18-207-5.

16. Christian, S.J. Natural fibre-reinforced noncementitious composites (biocomposites). No Nonconventional and Vernacular Construction Materials; Elsevier, 2020; lpp. 169-187.

17. Faruk, O.; Bledzki, A.K.; Fink, H.-P.; Sain, M. Biocomposites reinforced with natural fibers: 2000-2010. Prog. Polym. Sci. 2012, 37, 1552-1596.

18. Haraguchi, K. Biocomposites. No Encyclopedia of Polymeric Nanomaterials; Springer Berlin Heidelberg: Berlin, Heidelberg, 2015; lpp. 124-130.

19. Asokan, P.; Firdoous, M.; Sonal, W. Properties and potential of bio fibres, bio binders, and bio composites. Rev. Adv. Mater. Sci. 2012.

20. Pellis, A.; Malinconico, M.; Guarneri, A.; Gardossi, L. Renewable polymers and plastics: Performance beyond the green. N. Biotechnol. 2021, 60, 146-158.

21. Müller, C.; Kües, U.; Schöpper, C.; Kharazipour, A. Natural Binders. No; 2007; lpp. 347-381 ISBN ISBN13: 978-3-940344-11-3.

22. Kajikawa, S.; Horikoshi, M.; Tanaka, S.; Umemura, K.; Kanayama, K. Molding of wood powder with a natural binder. In Proceedings of the Procedia Engineering; 2017.

23. Shishkin, A.; Drozdova, M.; Kozlov, V.; Hussainova, I.; Lehmhus, D. Vibration-Assisted Sputter Coating of Cenospheres: A New Approach for Realizing Cu-Based Metal Matrix Syntactic Foams. Metals (Basel). $2017,7,16$.

24. Ozernovs, O.; Jevmenovs, I. Method for devulcanization of rubber and devulcanization catalyst for such purpose. Patent application PCT/IB2014/066580 2015, 8.

25. Lapkovskis, V.; Mironovs, V.; Irtiseva, K.; Goljandin, D.; Shishkin, A. Investigation of Devulcanised Crumb Rubber Milling and Deagglomeration in Disintegrator System. Key Eng. Mater. 2019, 800, $216-$ 220.

26. Polyakov, A.; Mironovs, V.; Shishkin, A.; Baronins, J. Preparation of Coal-Water Slurries Using a High Speed Mixer - Disperser. In Proceedings of the 4th International Scientific Conference Civil Engineering' 13; Jelgava, 2013; lpp. 77-81.

27. Shishkin, A.; Mironovs, V.; Vu, H.; Novak, P.; Baronins, J.; Polyakov, A.; Ozolins, J. Cavitation- 
Dispersion Method for Copper Cementation from Wastewater by Iron Powder. Metals (Basel). 2018, 8, 920.

28. Polyakov, A.; Polykova, E. Mixser-Disperser 2007.

29. Zong, Y.; Wan, Q.; Cang, D. Preparation of anorthite-based porous ceramics using high-alumina fly ash microbeads and steel slag. Ceram. Int. 2019, 45, 22445-22451.

30. Huo, W.; Zhang, X.; Chen, Y.; Lu, Y.; Liu, J.; Yan, S.; Wu, J.-M.; Yang, J. Novel mullite ceramic foams with high porosity and strength using only fly ash hollow spheres as raw material. J. Eur. Ceram. Soc. 2017, 1-8.

31. Zaccaron, A.; de Souza Nandi, V.; Bernardin, A.M. Fast drying for the manufacturing of clay ceramics using natural clays. J. Build. Eng. 2021, 33, 101877.

32. Ashby, M.F. Materials Selection in Mechanical Design; fourth.; Butterworth Heinemann: Oxford, 2010; ISBN 978-1-85617-663-7. 